\title{
SE TUDO É HISTÓRIA, POR QUE CONTINUAMOS A ESTUDAR PRÉ-HISTÓRIA NA ESCOLA? OS CONCEITOS DE HISTÓRIA E PRÉ-HISTÓRIA NOS LIVROS DIDÁTICOS CONTEMPORÂNEOS
}

\author{
IF EVERYTHING IS HISTORY, WHY DO WE CONTINUE TO STUDY PRE-HISTORY \\ AT SCHOOL? THE CONCEPTS OF HISTORY AND PRE-HISTORY IN \\ CONTEMPORARY SCHOOL BOOKS
}

Luiz Adriano Lucena Aragão ${ }^{1}$
Juliana Alves de Andrade ${ }^{2}$
Ana Lúcia do Nascimento ${ }^{3}$

\begin{abstract}
RESUMO: O trabalho problematiza a presença dos conceitos de História e Pré-história nos livros didáticos de História, aprovados pelo PNLD 2017-2019. Nossa intenção é demonstrar a força da tradição historiográfica brasileira na literatura didática, no modo de organizar os conteúdos, temas e conceitos no Livro didático, sem alterar a gramática da narrativa histórica. Usamos os pressupostos conceituais como História dos Conceitos (KOSELLECK, 1992), História (BLOCH, 2002), Pré-história (TRIGGER, 2004) e Livro Didático (FREITAS, 2009). Para analisar os livros didáticos lançamos mão da Análise de Conteúdo (BARDIN, 2010) para compreender os sentidos que circulam nas obras escolares. Como resultado da investigação os dados apontam que, mesmo após as exigências do PNLD, a narrativa do livro didático permanece organizada ainda no formato quadripartite (História Antiga, Medieval, Moderna e Contemporânea) e com uma semântica eurocêntrica, embora, sejam observados que o livro incorpora novos sentidos aos termos História e Pré-história com o passar dos anos. Essa mudança nos sentidos que os conceitos carregam, nos permite afirmar que os livros didáticos de história contemporâneos estão em sintonia com a produção epistemológica do campo da História, logo, buscam considerar os diferentes sujeitos e as múltiplas experiências históricas.
\end{abstract}

Palavras-chave: História. Pré-História. Livro Didático. PNLD

ABSTRACT: The work problematizes the presence of the concepts of History and Prehistory in the History textbooks, approved by the PNLD 2017-2019. Our intention is to demonstrate the strength of the Brazilian historiographical tradition in the didactic literature, in the way of organizing the contents, themes and concepts in the Didactic Book, without changing the grammar of the historical narrative. We use conceptual assumptions such as History of Concepts (KOSELLECK, 1992), History (BLOCH, 2002), Prehistory (TRIGGER, 2004) and Textbook (FREITAS, 2009). To analyze textbooks, we used Content Analysis (BARDIN, 2010) to understand the meanings that circulate in school works. As a result of the investigation, the data indicates that, even after the requirements of the PNLD,

1 Mestre em História; Graduado em História; Professor de História e Aux. Em Assuntos Educacionais - IFPE

2 Pós-doutorado em Educação pela Universidade de Passo Fundo (UPF). Doutora e Mestre em História; Graduada em História; Professora adjunta da Universidade Federal Rural de Pernambuco e do Mestrado Profissional em Ensino de História-ProfHistória (UFPE/UFRPE).

3 Doutora e Mestre em Arqueologia; Graduada em História; Professora Associada IV da Universidade Federal Rural de Pernambuco e do Programa de Pós-Graduação em História-PGH. 
the textbook narrative remains organized in a quadripartite format (Ancient, Medieval, Modern and Contemporary History) and with a Eurocentric semantics, although it is observed that the book incorporates new meanings to the terms History and Prehistory over the years. This change in the meanings that the concepts carry, allows us to affirm that the contemporary history textbooks are in line with the epistemological production of the field of History, therefore, they seek to consider the different subjects and the multiple historical experiences.

Keywords: History. Prehistory. Textbook. PNLD.

\section{Introdução}

O título do presente artigo, além de ser provocativo, carrega consigo uma história de um debate proposto por Paul Veyne na obra "como se escreve a história: Foucault revoluciona a história" em 1971 ao afirmar que: "Tudo é histórico, logo, a História não existe. Na ocasião, o autor chamava a atenção para o fato de que era necessário que a produção historiográfica não fizesse distinções ou hierarquizações de histórias, narrativas ou fontes. Segundo Paul Veyne, a historiografia naquele momento, precisava fazer um deslocamento, no sentido, de perceber que era preciso migrar da ideia de História (com inicial maiúscula, no singular e de caráter universal) para histórias de, e, assim, escrever e refletir sobre diferentes experiências e sujeitos. Esses questionamentos levantados por Paul Veyne, tornou-se paradigma no campo e influenciou o modo como uma geração de pesquisadores e intelectuais produzem e escrevem a história. Assim, tomando como ponto de partida esses pressupostos de Paul Veyne, nos propomos a analisar os livros didáticos de história que circulam nas escolas brasileiras por intermédio do Programa Nacional do Livro Didático (PNLD) no período de 2017-2019.

O livro didático é um objeto cultural complexo que carrega muitas memórias e histórias, é fonte de pesquisa para diversas temáticas e diferentes grupos de pesquisa. Nesse sentido, podemos pensar, em comum com Flávia Caimi (2013), nas seguintes categorias, objetos de pesquisa nas dissertações e teses nas últimas três décadas: a) etnias e pluralidade, b) linguagens, c) cidadania, d) usos do livro didático de História pelo professor, e) gênero, f) análise de conteúdo, g) História do ensino de História, h) concepções do livro didático, i) categorias de aprendizagem e j) historiografia. Essa classificação adotada pela autora contribui 
para os pesquisadores do campo do Ensino de História ampliar os debates e perceber as mudanças no curso dos estudos realizados.

Por mais difícil que seja definir o livro didático, como afirma Alain Choppin (2004), nos pautaremos nas ideias de Itamar Freitas (2009) para quem o livro é um objeto impresso em papel, tem uma utilização didática, para isso é planejado e organizado em formato linear, composto por textos e imagens, postos em sequência, com a finalidade de transmitir saberes inerentes a uma disciplina escolar (FREITAS, 2009, p.13).

Assim, entendendo essas peculiaridades da fonte, o presente estudo visa problematizar a permanência do conceito de Pré-história e a sua relação com a ideia de História nos livros didáticos de História, aprovados pelo PNLD 2017-2019. Nossa intenção é demonstrar a força da tradição historiográfica oitocentista brasileira na literatura didática, mesmo após a organização e consolidação do Programa Nacional do Livro Didático-PNLD, responsável pela avaliação da qualidade historiográfica e pedagógica dos livros didáticos e que tenta romper com alguns pressupostos da historiografia tradicional.

Para tal, faremos uma leitura do livro didático a luz da estratégia analítica da Análise de Conteúdo (BARDIN, 2010), usamos os pressupostos conceituas desenvolvidos nas pesquisas sobre a História dos Conceitos (KOSELLECK, 1992), bem como os conceitos de: História (BLOCH, 2002), Pré-história (TRIGGER, 1973) e Livro didático (FREITAS, 2009). Para entender as estratégias utilizadas pelo mercado editorial e pelos autores de livros didáticos, partimos de algumas indagações: Quais as coleções utilizam o conceito de História e Pré-história? Quais são as ressignificações que os conceitos de Pré-história e História sofreram nos livros didáticos? Quais são as concepções historiográficas sobre História e Préhistória presentes nas coleções didáticas mais distribuídas no PNLD 2017-2019?

Ao buscar responder às questões elencadas acima, percebemos que as estratégias utilizadas pelo mercado editorial para não romper com a relação existente entre as exigências dos editais do PNLD, a historiografia escolar e a cultura escolar foi inicialmente permanecer com a semântica eurocêntrica na narrativa do livro didático, e, depois substituindo o termo Pré-história, por histórias dos povos indígenas anteriores ao período da colonização. Nesse sentido, a pesquisa demonstra que, mesmo após as reconfigurações dos saberes históricos 
a serem ensinados nos livros didáticos, por conta da forte influência da historiografia francesa (Escola dos Annales, História Cultural, Nova História Cultural), o material permanece organizado a partir da perspectiva cronológica linear de tempo e ambientado com forte influência eurocêntrica, mas sem se eximir de problematizar os conceitos de História e Pré-história. A estratégia do livro é adotar um novo significado para a semântica eurocêntrica (palavra, termo, discurso) e explicar os fatos e acontecimentos históricos selecionados pelo material.

Para entender o livro didático e a complexidade de sua escrita é necessário considerar que as transformações historiográficas vividas no Brasil e como elas impactam diretamente a produção didática. Para Raquel Glezer (1984), a narrativa didática produzida na década 1980 estava desconectada da produção historiográfica acadêmica e distante do cotidiano escolar. Isso se deve em grande parte as ações de restrição do governo civil-militar (1964-1985) que se empenhou para controlar as opiniões e os pensamentos dos cidadãos, suprimindo grande parte da formação geral e das humanidades no currículo oficial, sob a alegação de combater toda e qualquer crítica ao regime autoritário.

Para Décio Gatti (2004), de 1970 a 1990 a política pública para o setor editorial de livros didáticos se configurou em uma ação distributiva de livros para as escolas do país sem ter um envolvimento mais qualitativo com outras questões do sistema educacional brasileiro (GATTI, 2004, p.366). Esse distanciamento para a produção de um livro mais qualitativo, segundo Glezer (1984), tentou ser minimizado com a modernização dos livros didáticos, tanto nos aspectos visuais como as cores, inserção de gráficos, mapas, quanto na linguagem textual, com textos complementares, linguagem mais simplificada, utilização do vocabulário corrente e do cotidiano. Contudo, os livros permaneceram com conceitos complexos, faixa etária indefinida para determinado conteúdo e uma bibliografia clássica consultada pelos autores dos livros no período em questão, e isso deu o compasso para que novos livros fossem editados sobre velhas ideias. Mantiveramse a mesma ideia de controle do conteúdo do livro didático sob o viés de uma História tradicional. (GLEZER, 1984, p. 153).

A partir da década 1990, pós-abertura política, o Ensino de História é reformulado com algumas mudanças importantes, como aponta Selva Guimarães 
(2012), substituição no currículo da disciplina de Estudos Sociais por História e Geografia, no Ensino Básico. Extinção como base em dispositivos legais das disciplinas Educação Moral e Cívica, Organização Social e Política do Brasil e Estudos de Problemas Brasileiros. Extinção das licenciaturas de curta duração. Essa movimentação possibilitou algumas transformações na política educacional do país.

E no bojo dessas transformações com o objetivo de avaliar e qualificar o livro didático tem-se, em 1985, a instituição do Programa Nacional do Livro Didático - PNLD - pelo então, presidente da república José Sarney que governou o Brasil no período de 1985-1990. O PNLD é o maior programa, pautado em diretrizes educacionais, de avaliação de distribuição de livros didáticos do país. Para Flávia Caimi (2015):

[...] até meados da década de 1980 não havia procedimentos avaliativos institucionais sistemáticos sobre o livro didático no Brasil. No ano de 1985, pelo Decreto no 91.542, é criado o Programa Nacional do Livro Didático (PNLD), dando-se início às avaliações pedagógicas periódicas para a qualificação do livro didático, com base em critérios sistemáticos e rigorosos (CAIMI, 2015, p. 528).

É importante salientar que, na metade da década de 1990, as pesquisas acadêmicas adentram o universo da literatura didática. E em relação ao PNLD, em 1994, é formulado um documento base que estabelece a "Definição de Critérios para Avaliação dos Livros Didáticos" MEC/FAE/UNESCO. Esses critérios, a partir de 1996, passam a fazer parte do Guia do Livro Didático, um manual que estabelece novos critérios avaliativos, novas temáticas e recursos didáticos para compor a literatura escolar. Esses critérios, estão presentes nas disciplinas do ensino básico e na área de História, com a função de alinhar novos pressupostos teóricos e metodológicos do conhecimento histórico aos livros didáticos de História.

Desse alinhamento vem a reescrita do material didático, está reescrita, presente na narrativa do livro, com o tempo vai paulatinamente passando por transformações, isso nos interessa para pesquisar sobre o material didático. Para refletir sobre os resultados produzidos nesta pesquisa discutiremos como os livros didáticos de História apresentam os conceitos de Pré-história e História, as estratégias utilizadas na escrita didática para justificar a permanência do termo (Pré-história) nos livros e as ressignificações conceituais presentes nos termos. 


\section{Quais livros didáticos falam sobre História e Pré-história?}

Para responder ao questionamento acima recorremos ao conjunto documental que serviu de fonte para as nossas reflexões, os livros didáticos mais distribuídos para nas escolas públicas brasileiras, conforme dados do FNDE de $2017^{4}$. Essas 5 (cinco) coleções de livros didáticos representam um número significativo de acesso de criança ao conhecimento histórico escolar, conforme o volume de livros distribuídos, como observarmos na tabela 1, a seguir:

Tabela 1: Coleções mais distribuídas do Ensino Fundamental (anos finais)

\begin{tabular}{|c|c|c|c|c|c|}
\hline 0 & Colocaçã & $\begin{array}{l}\text { Nome } \\
\text { da coleção }\end{array}$ & Editor & Autor & $\begin{array}{l}\text { Quantidad } \\
\text { e de exemplares } \\
\left(6^{\circ} \text { ano }\right)\end{array}$ \\
\hline & 10 & $\begin{array}{l}\text { História } \\
\text {, Sociedade e } \\
\text { Cidadania }\end{array}$ & Editora & $\begin{array}{l}\text { Alfredo } \\
\text { Boulos Júnior }\end{array}$ & 923.792 \\
\hline & 20 & $\begin{array}{l}\text { Projeto } \\
\text { Araribá }\end{array}$ & $\begin{array}{l}\text { Editora } \\
\text { Moderna }\end{array}$ & $\begin{array}{l}\text { Maria } \\
\text { Raquel } \\
\text { Apolinário }\end{array}$ & 478.724 \\
\hline & 30 & $\begin{array}{l}\text { Vontad } \\
\text { e de Saber }\end{array}$ & Editora & \begin{tabular}{l}
\multicolumn{1}{c}{ Adrian } \\
a Dias; Keila \\
Grinberg; \\
Marco \\
Pellegrini
\end{tabular} & 315.013 \\
\hline & $4^{\circ}$ & $\begin{array}{l}\text { Projeto } \\
\text { Mosaico }\end{array}$ & $\begin{array}{c}\text { Editora } \\
\text { Scipione }\end{array}$ & $\begin{array}{l}\text { Claudi } \\
\text { o Vicentino; } \\
\text { José Bruno } \\
\text { Vicentino }\end{array}$ & 288.248 \\
\hline & 50 & Historia & $\begin{array}{l}\text { Editora } \\
\text { Saraiva }\end{array}$ & $\begin{array}{l}\text { Gilbert } \\
\text { o Cotrim; } \\
\text { Jaime } \\
\text { Rodrigues }\end{array}$ & 219.441 \\
\hline
\end{tabular}

4 Através do EDITAL DE CONVOCAÇÃO 02/2015 - CGPLI PNLD 2017 ocorreu o processo de inscrição e avaliação de obras didáticas para o PNLD. Houve a convocação de editores para o processo de aquisição de obras didáticas destinadas aos estudantes e professores dos anos finais do ensino fundamental das escolas públicas federais e as que integram as redes de ensino estaduais, municipais e do Distrito Federal, participantes do PNLD. O resultado da aprovação foi publicado pela portaria No 13, de 23 de junho de 2016. O PNLD aprovou 14 coleções de História para os anos 2017, 2018 e 2019. 
Os livros eleitos como fonte, conforme tabela 1, representam artefatos que são utilizados por um número significativo de crianças (coluna quantidade de exemplares - tabela 1). O PNLD (2017-2019) aprovou 14 (catorze) coleções para a área de História no Ensino Fundamental (anos finais), em que cada coleção é composta por 4 (quatro) volumes separados por anos escolares do 60 ao 90 ano. As 5 (cinco) coleções utilizadas neste estudo perfaz um total de 2.225,218 de exemplares. O que corresponde a aproximadamente $68 \%$ dos livros comprados pelo governo e distribuídos aos alunos, de acordo com a tabela 2, a seguir:

Tabela 2: Coleções mais distribuídas do Ensino Fundamental

(anos finais, $6^{\circ}$ ano)

\begin{tabular}{|lll|}
\hline Colocação & $\begin{array}{c}\text { Quantidade } \\
\text { De exemplares } \\
\left(6^{\circ} \text { ano }\right)\end{array}$ & $\begin{array}{l}\text { Percentual } \\
\text { De }\end{array}$ \\
para & $\begin{array}{l}\text { distribuição } \\
\text { as escolas }\end{array}$ \\
\hline $1^{\circ}$ ao $5^{\circ}$ & 2.225 .218 & $68 \%$ \\
\hline $6^{\circ}$ ao $14^{\circ}$ & 718,498 & $32 \%$ \\
\hline
\end{tabular}

Fonte: FNDE. Tabela sistematizada por Aragão, 2019. Disponível em: http://www.fnde.gov.br/programas/programas-do-livro/livro-didatico/dadosestatisticos.

Após selecionar as coleções para a análise, fizemos uma nova filtragem para nos aproximar do problema de investigação: os conceitos de Pré-história e História nos livros didáticos. Na cultura escolar, o debate sobre o conceito de História e Pré-história aparece no currículo do $6^{\circ}$ ano, nos capítulos iniciais do livro. Utilizouse a metodologia de análise de conteúdo para separar os textos mais significativos dos livros, explorando os aspectos do ensino e aprendizagem e a construção das relações de saber presentes nos conceitos analisados nos livros didáticos. Minayo (2009) nos diz que nas Ciências Sociais é a abordagem qualitativa que nos faz perceber a realidade que não pode ou não deve ser quantificada, mas trabalhada na perspectiva dos significados e dos valores (MINAYO, 2009, p.21).

\section{História e Pré-história: os múltiplos sentidos de duas conhecidas palavras}

A ideia inicial quando se remete ao termo História, é pensar como a Antiguidade, na Grécia antiga, no século V, concebeu esse termo. Para os gregos a palavra possuía duas acepções: memorizar os feitos humanos grandiosos e servir de protótipo para as ações futuras dos homens na pólis grega. Esse pensamento 
vem da concepção de uma natureza universal e imutável do homem e corroborou para uma lógica de que em circunstâncias equivalentes os seres humanos agiriam da mesma forma, nesse sentido, na Antiguidade Clássica o conhecedor da História não cometeria os mesmos erros dos seus antepassados. (KOSELLECK, MEIER, et al., 2013, p. 42).

Esse primeiro sentido atribuído a História, formulou um modelo a ser seguido baseado em fatos extraordinários, e seguido por muitos anos. Para os romanos o significado do termo é ampliado, passa a ter uma função política e moral. Os assuntos históricos diziam respeito à maneira de como governar, liderar e guiar os cidadãos. Eram discutidos os valores da sociedade, os princípios, comportamentos, costumes, leis, as motivações e paixões das ações humanas em dado contexto.

A ideia de um norteamento das ações políticas e morais a partir da observação dos acontecimentos consubstanciou na História o sentido de experiência, de sabedoria, de legado. Segundo o historiador Durval Albuquerque (2012):

\begin{abstract}
A História cumpria, assim, o desígnio de educar as gerações vindouras, de educar moral e politicamente as futuras elites dirigentes, transmitindo experiência e sabedoria para os próximos governantes.

[...] A História ocupava-se dos acontecimentos do presente. Seu recurso ao passado dava-se à medida que esse ajudava a tornar inteligíveis os eventos extraordinários que o narrador presenciava e dirigia-se ao futuro à medida que se justificava pelas memórias e ensinamentos que transmitia. (ALBUQUERQUE, 2012, p. 22).
\end{abstract}

$\mathrm{Na}$ modernidade temos uma ruptura com outro modelo historiográfico, o teológico medieval, no sentido de que houve uma secularização dos saberes históricos. "A esperança escatológica cedeu lugar ao futuro terrestre" (REIS, 2012, p. 26), Koselleck (2006) nos fala em relação à modernidade, de uma linha utópica na qual o homem consegue perceber o conhecimento acumulado pela humanidade e de posse desse acúmulo passa a crer no progresso irrestrito da sociedade. Essa lógica contribuiu para que mais adiante o Iluminismo do século XVIII reafirmasse a filosofia na razão e no progresso humano. O homem do iluminismo se vê como mentor da História capaz de acelerar as mudanças e as transformações em curso e de produzir grandes narrativas, de produzir um pensamento universal. Um sentido de linearidade se apresenta para o registro da História. 
Já o termo Pré-história surge para designar tanto um campo disciplinar, quanto experiências humanas que não possuíam códigos culturais como a escrita. O termo começa a ser usado, em meados do século XIX, pelos pesquisadores que tinha como objetivo os estudos sobre os vestígios materiais da humanidade. Esse movimento foi liderado pelos estudos arqueológicos. Dois grupos são protagonistas: os escandinavos e os franceses/ingleses. As novas técnicas de datações e as condições de estabelecer uma melhor cronologia para os materiais encontrados em sítios arqueológicos na Dinamarca permitiram criar modelos para estudos da arqueologia. Do lado da França e da Inglaterra foram desenvolvidos estudos do período paleolítico que permitiram verificar uma maior profundidade temporal nos estudos sobre a evolução humana.

Foi atribuído ao inglês Daniel Wilson em seu livro The Archaeology and Prehistoric Annals of Scotland o uso inicial do termo. A ideia trazida por Wilson define a Pré-história "como um estudo relacionado a períodos ou tipos de dados históricos, cujo registro não fora intencional" (TRIGGER, 1973, p.04). O sentido dado pelo pesquisador britânico ao termo pode ser identificado como uma maneira clássica e etnocêntrica de classificar os saberes históricos, intencionais e não intencionais. A apropriação do termo Pré-história como algo que inicia ou antecede uma História revela o trânsito dessa denominação, seja na esfera acadêmica ou escolar. Esse sentido perdura desde o século XIX, segundo Chris Gosden, diretor do Instituto de Arqueologia da Universidade de Oxford, e nos remete a ideia de que termos como ante-história que poderia substituir o termo Pré-história nunca conseguiu se firmar e por força da tradição, o termo se tornou um conceito representativo dos estudos que envolvem o passado mais longínquo da História humana (GOSDEN, 2012, p.27).

Com relação aos sentidos atribuídos ao termo Pré-história, observamos que a partir do século XIX, vindo de uma tendência europeia, o termo começa a significar os seguintes aspectos: a) o período da História em que não há evidência de documentos escritos; b) possui a maior temporalidade como período histórico e c) é fonte de estudos para Arqueologia. Notamos que essas três perspectivas até hoje circulam nos livros didáticos.

O conceito de Pré-história tem se revelado nos dicionários, enciclopédias e literatura acadêmica como um conceito positivista. A palavra não apresenta 
alterações semânticas significativas desde o século XIX. Assim, o estudante do ensino fundamental ao pesquisar o termo Pré-história, em qualquer dispositivo, terá contato com um conceito do século XIX que carrega consigo pontos questionáveis como veremos na análise dos livros didáticos. Já a palavra História, com preceitos científicos, a partir do século XIX, terá três grandes paradigmas que Ihe servirá de alicerce teórico: o positivismo, o historicismo e o materialismo histórico. O positivismo, com o legado do iluminismo, procurou identificar as leis que regiam os fenômenos históricos através da objetividade e dos métodos de análise documental. Diziam-se imparciais na produção da História e na análise dos documentos. Os historiadores positivistas procuraram perceber a História através de generalizações que permitissem se guiar por um viés de sentido único que contemplasse toda a História da humanidade.

Os historicistas procuraram, de forma diferente dos positivistas, compreender a História sob suas particularidades através da análise sistemática das sociedades em seu processo histórico (BARROS, 2011, p. 54). Com o objetivo sistemático de analisar as evidências históricas, os historicistas desenvolveram a crítica documental - a crítica das fontes para analisar as experiências do passado. O método dos historicistas constitui a principal contribuição da Escola Histórica Alemã para a historiografia.

O conceito de História passará por uma grande ressignificação no século XX, sobretudo, por conta do movimento historiográfico conhecido como a Escola dos Annales. De matriz francesa, dividido em quatro gerações de estudiosos, que teve início no ano 1929, os historiadores dos Annales trouxeram um novo olhar para a História. Com eles surgem a História-problema em detrimento da História-factual tão defendida no século XIX. Algo em comum as quatro gerações dos Annales foi a constante crítica ao factualismo por não apresentar problematizações. A História para os historiadores dos Annales se propõe interpretativa, problematizadora, questionadora, apoiada em hipóteses, capaz de rever acontecimentos por diferentes visões, com novas leituras e de se mover por fontes documentais diversas, bem mais amplas do que todos os tempos de outrora da historiografia.

No século $X X$, houve na historiografia uma ressignificação nos conceitos de narrativa, os acontecimentos, a pesquisa, a análise documental, o método científico. Sob o olhar dos Annales, esses elementos foram problematizados, com 
essa nova perspectiva o papel do historiador se faz mais proeminente no aspecto subjetivo e na forma de interpretar as fontes e de operar com a escrita da História. Esse período foi marcado pelas renovações historiográficas capitaneadas pelo movimento dos Annales. A partir desse movimento, a produção historiográfica já não utilizará o fato pelo fato, mas a ideia de que a História é um processo que perpassa pela construção do historiador em decorrência da problemática elencada. E essa problemática, segundo Bloch (2002), somente será revelada se o historiador souber interrogar os documentos de que dispõe, tirando dos testemunhos e das fontes respostas as suas inquietações, pois os documentos não falam por si só. (BLOCH, 2002, p. 27).

Nesse sentido, o presente trabalho busca explicar a seguir, o lugar dos termos Pré-história e História nos livros didáticos, buscando acompanhar as estratégias dos autores ao redefinir o sentido que a palavra representa.

\section{A ressignificação conceitual dos termos História e Pré-história nos livros didáticos}

Para análise das coleções utilizou-se a metodologia de análise de conteúdo de Bardin (2010), com recortes na narrativa principal dos livros didáticos, separados por categorias para guiar e embasar a pesquisa, que resultou na montagem de quadros descritivos e comparativos dos termos (História e Préhistória). A análise de conteúdo, aqui proposta, garante meios sistemáticos e objetivos para fazer descrições de conteúdos de mensagens, de dados indicadores (quantitativos ou não) que ao serem analisados permitem construir inferências de tais mensagens (BARDIN, 2010, p.38). Para tanto, elencamos 3 (três) categorias: a) terminologia, b) adequação conceitual e c) atualização historiográfica. A seguir nos deteremos à observação categorizada.

A terminologia diz respeito ao conjunto de termos específicos ou sistema de palavras que designam os vocábulos próprios de uma disciplina ou uma área do conhecimento, por exemplo, na matemática, economia ou botânica. Uma terminologia também pode ser relacionada às expressões particulares de autor literário ou ainda pode representar um acervo de palavras utilizadas para determinado contexto. Nesse sentido, buscamos observar a terminologia usada 
pelos livros didáticos para se referir aos conceitos pesquisados, percebendo a utilização dos vocábulos.

Ao observamos as palavras usadas nos livros didáticos para expressar os termos História e Pré-história, destacamos, no quadro 1, a seguir, as palavras que sintetizam ideias-chave. Dentre as palavras relacionadas à História, nas 5 (cinco) coleções destacam-se: mudança, permanência, passado, presente, tempo. Essas palavras ganham sentidos para a formação de um conceito de História quando são utilizadas dentro de um contexto social. Tal conceito de História apresenta uma ampliação de sentido quando na narrativa didática se somam mais alguns verbetes: simultaneidade, ruptura, acontecimento, memória, esses termos embasam a construção de uma definição de História pela convergência de mais algumas palavras: informação, conhecimento, construção interpretativa e narração. É observado que o termo História permanece o mesmo, mas o sentido é ampliado.

Ao analisar a terminologia extraída das coleções percebe-se uma confluência de palavras para o que se entende por História hoje: uma ciência cujo objetivo é entender as transformações, as permanências, os usos do passado, a memória, a cultura das sociedades em diferentes tempos e espaços para apontar caminhos, através de um viés crítico, que reparem injustiças, políticas desastrosas e posturas do próprio homem que degradem a condição humana (ARAGÂO, 2019, p.76).

Observando as palavras que foram usadas em outros momentos para conceituar a História como acontecimento, memória, narrativa e interpretação. Tem-se uma ligação com o conjunto de palavras encontradas nos livros analisados. Nesse sentido, identificamos que o termo História apresenta uma definição alinhada com o debate atual no universo acadêmico.

Em relação ao termo Pré-história também observamos os movimentos de alteração, ampliação do conceito, manutenção da semântica e silenciamento do termo. Percebe-se que os livros trazem o conceito expresso em suas páginas, justificando uma periodização tradicional. E identificam no termo e no uso da periodização como algo atrasado e etnocêntrico (APOLINÀRIO, 2014, p. 28). Está relacionado aos sentidos como escrita, divisão, primitivo seguido de uma explicação crítica para os usos desses termos. Ou seja, os livros apresentam uma problematização da historiografia oitocentista tradicional que considerava 
primitiva a cultura dos grupos populacionais que não dominavam o código da escrita, como os americanos, africanos e asiáticos. Segundo Corrêa (2013), essa visão historiográfica ganhou força também no século XX quando a historiografia francesa comparou os povos ágrafos aos povos pré-históricos.

Por outro lado, encontramos livros que não fazem uso expresso do termo Pré-história (História, sociedade e cidadania - BOULOS JUNIOR, 2015 e Vontade de Saber - PELLEGRINE, 2015) e utilizam a expressão Períodos Históricos ou somente a palavra História. É nesse contexto de problematização dos conceitos nos livros didáticos que nos perguntamos se tudo é História, por que estudamos a Pré-história na escola? Para mostrar que novos questionamentos têm sido feitos e que a leitura histórica e arqueológica pautada no método histórico no campo da arqueologia considera proeminente uma visão menos colonizadora que leve em consideração os fatores históricos associados ao lugar das descobertas. Isso indica que não podemos associar o passado pré-colonial (Brasil) ao passado pré-histórico europeu (CORREA, 2013, p. 27).

Em síntese, os livros associam de forma crítica os termos divisão, etnocêntrico, primitivo, atrasado e periodização tradicional para levar o aluno a refletir sobre a ligação do termo Pré-história que nas coleções é apresentado como um conceito em desconstrução que se mantém nos livros didáticos por força da tradição escolar. Por isso, o conceito de Pré-história, nos livros didáticos, se encontra em descompasso com as críticas mais atuais da arqueologia e não pode ser utilizado sem a devida contextualização e problematização uma vez que alguns algumas palavras associadas ao termo indicam a ideia de "povos primitivos", conforme, quadro 1 , apresentado a seguir: 


\section{Quadro 1 - Terminologia}

\begin{tabular}{|c|c|c|c|}
\hline Coleção (livro) & Categoria & História & Pré-história \\
\hline $\begin{array}{c}\text { História, Sociedade e } \\
\text { Cidadania }\end{array}$ & \multirow{5}{*}{ Terminologia } & $\begin{array}{l}\text { "A História estuda justamente o processo de } \\
\text { mudanças ocorridas nas sociedades. Incluem-se } \\
\text { aí as mudanças no campo da tecnologia, da moda, } \\
\text { da alimentação, da construção de moradias, do } \\
\text { lazer, entre outras." } \\
\text { "mudanças"; "permanências"; "sociedade" } \\
\text { "passado"; "presente"; "tempo". p.13-14 }\end{array}$ & $\begin{array}{l}\text { "Divisão tradicional da História"; "fatos } \\
\text { "importantes para os povos da Europa"; "há } \\
\text { povos que nâo utilizam a escrita". p. } 40\end{array}$ \\
\hline Projeto Araribá & & $\begin{array}{l}\text { "Hoje está claro para os historiadores que a } \\
\text { história não é o retrato do passado, mas uma } \\
\text { hipótese, ou seja, uma interpretação } \\
\text { fundamentada sobre parte do passado." } \\
\text { "ciência humana"; "passadol;; "presente"; } \\
\text { "acontecimentos"; "futuro"; "pergunta" } \\
\text { "investigar". p. 18-20. }\end{array}$ & $\begin{array}{l}\text { "A periodização mais utilizada em livros de } \\
\text { história foi criada por estudiosos europeus"; } \\
\text { "anula a história de outros povos". p.28 }\end{array}$ \\
\hline Vontade de Saber & & $\begin{array}{l}\text { "ações dos seres humanos no tempo e no } \\
\text { espaço"; "transformações"; "permanências"; } \\
\text { "rupturas"; "simultaneidade"; "passado"; } \\
\text { "presente"; "sociedade"; "cultura" } \\
\text { "interpretação"; "análise"; "diferenças"; } \\
\text { "semelhanças" p. 16-17. }\end{array}$ & O livro não faz uso do termo Pré-história. \\
\hline Projeto Mosaico & & $\begin{array}{l}\text { "ciência"; "transformação"; "permanência"; } \\
\text { "sociedade"; "acontecimento"; "sentido"; } \\
\text { "passado". p. 11-15 }\end{array}$ & $\begin{array}{l}\text { "não desenvolveram a escrita"; "divisão"; } \\
\text { "invenção da escrita"; "atrasados"; } \\
\text { "primitivos".p. } 25\end{array}$ \\
\hline Historiar & & $\begin{array}{l}\text { O livro abre o capítulo de introdução aos estudos } \\
\text { históricos com a temática de Cultura e } \\
\text { Diversidade. } \\
\text { "sentido"; "cultura"; "informações"; } \\
\text { "conhecimento"; "mudanças"; "passado"; } \\
\text { "narração"; "construção"; "memória" } \\
\text { p.10,16.21 e 22. }\end{array}$ & $\begin{array}{l}\text { "atividade cultural" } \\
\text { "etnocentrismo" "escrita"; "tradicional". p.40 }\end{array}$ \\
\hline
\end{tabular}

Fonte: ARAGÃo, 2019, p. 75

A segunda categoria analisada é a adequação conceitual "que é vista com a relação de sentido, de pertinência e relevância de um texto para articular os argumentos de um dado tema" (ARAGÃO, 2019, p. 78). Um dos fatores que mais indica a adequação conceitual é a pertinência. Então, observamos a importância do debate sobre História e Pré-história sob o aspecto pertinência para a formação cognitiva das crianças.

É necessário distanciar da disciplina História a ideia bastante condensada na cultura escolar de ser uma disciplina decorativa decorrente da transmissão de conteúdos factuais, um conjunto de informações sequenciais, que tratam de um passado distante passível de ser memorizado mecanicamente. A seguir analisamos o quadro 2: 


\section{Quadro 2 - Adequação conceitual}

\begin{tabular}{|c|c|c|c|}
\hline Coleção (livro) & Categoria & História & Pré-história \\
\hline $\begin{array}{l}\text { História, Sociedade } \\
\text { e Cidadania }\end{array}$ & \multirow[t]{2}{*}{$\begin{array}{l}\text { Adequação } \\
\text { conceitual }\end{array}$} & $\begin{array}{l}\text { "A História estuda justamente o processo de } \\
\text { mudanças ocorridas nas sociedades. Incluem-se } \\
\text { aí as mudanças no campo da tecnologia, da moda, } \\
\text { da alimentação, da construção de moradias, do } \\
\text { lazer, entre outras. } \\
\text { Mas a História não estuda apenas as mudanças. } \\
\text { Estuda também as permanências, ou seja, } \\
\text { aquilo que, mesmo com o passar dos anos, não } \\
\text { mudou ou mudou pouco." } \\
\text { "[...] A História estuda as mudanças e também as } \\
\text { permanências. Procura perceber o modo como as } \\
\text { pessoas viviam nos tempos antigos e como vivem } \\
\text { hoje, bem como a relação entre aqueles tempos e os } \\
\text { tempos atuais. Ou seja, a História estuda o tempo } \\
\text { passado e também o presente. Por isso, pode-se } \\
\text { dizer que a História é o estudo dos seres } \\
\text { humanos no tempo." } \\
\text { p.13 e } 14\end{array}$ & $\begin{array}{l}\text { "História e conhecimento } \\
\text { Para construir um conhecimento sobre determinado povo ou } \\
\text { episódio, o historiador necessita do saber elaborado pelos } \\
\text { profissionais de outras áreas, como os arqueólogos, os } \\
\text { geógrafos, os biólogos, entre outros. Os arqueólogos estudam } \\
\text { os grupos humanos por meio dos vestigios materiais deixados } \\
\text { por eles, como restos de casas, instrumentos de trabalho, } \\
\text { pinturas feitas em rochas e vasos. O pedaço de um machado } \\
\text { de pedra escavado por um arqueólogo e examinado em } \\
\text { laboratório pode nos contar sobre a idade daquela pedra } \\
\text { e o modo de vida do povo que utilizou aquele machado. } \\
\text { Vasos, potes e jarros para beber água estão entre os achados } \\
\text { mais comuns nas escavações arqueológicas; porém, são } \\
\text { poucos os encontrados inteiros. } \\
\text { Assim, incorporando os saberes acumulados por outros } \\
\text { estudiosos, o historiador vai aumentando seu conhecimento } \\
\text { sobre os seres humanos e sua trajetória ao longo do tempo." } \\
\text { p.19 }\end{array}$ \\
\hline \multirow[t]{2}{*}{ Projeto Araribá } & & $\begin{array}{l}\text { "[...] Ao investigar o passado, os historiadores } \\
\text { reúnem muitos documentos e versões diferentes } \\
\text { sobre o periodo em estudo; em seguida cruzam } \\
\text { todas as informações, verificam se elas são } \\
\text { confiáveis e escrevem uma narrativa consistente } \\
\text { sobre os acontecimentos."; } \\
\text { "As pessoas comuns também são sujeitos da } \\
\text { história } \\
\text { Dois trabalhos teóricos nas ciências humanas foram } \\
\text { responsáveis pela introdução de novos temas e } \\
\text { personagens nas pesquisas de história, mudando } \\
\text { radicalmente a forma como o passado era visto e } \\
\text { estudado. } \\
\text { O primeiro trabalho foi feito pelos alemães Karl Marx } \\
\text { (1818-1883) e Friedrich Engels (1820-1895). Eles } \\
\text { elaboraram a ideia de que as mudancas na história }\end{array}$ & $\begin{array}{l}\text { "Para muitos pesquisadores, a história teve inicio quando } \\
\text { os hominideos começaram a fabricar, de maneira regular, } \\
\text { utensílios de pedra com um formato e uma intenção } \\
\text { determinada." } \\
\text { "Ao estudar o passado primitivo da história humana, os } \\
\text { pesquisadores deram o nome de Paleolítico" } \\
\text { "Aproximadamente } 12 \text { mil anos atrás, iniciou-se também uma } \\
\text { mudança na fabricação de instrumentos. Os grupos humanos } \\
\text { começaram a produzir enxadas, foices, pilóes e machados } \\
\text { com pedras polidas, inaugurando o periodo que os estudiosos } \\
\text { denominaram Neolitico" p. } 43 \text { e } 46 \text {. }\end{array}$ \\
\hline & & $\begin{array}{l}\text { tinham sido movidas sempre pela luta entre a classe } \\
\text { dominante e a classe oprimida. } \\
\text { [...] No trabalho que desenvolveram, passaram a } \\
\text { valorizar a ação das pessoas comuns, suas } \\
\text { condições de trabalho, suas lutas, seu cotidiano, } \\
\text { seus costumes. Ė a chamada história vista de baixo. } \\
\text { O segundo trabalho transformou os estudos de } \\
\text { história começou a ser publicado por historiadores } \\
\text { franceses em } 1929 \text { e ficou conhecido como Escola } \\
\text { dos Annalesł O grupo francês ampliou a noção que } \\
\text { se tinha de documento histórico. Além das fontes } \\
\text { escritas, pinturas, esculturas, ferramentas, } \\
\text { moradias, fósseis e vários outros registros passaram } \\
\text { a ser examinados como fonte para compreender o } \\
\text { passado".p.20-21 }\end{array}$ & \\
\hline
\end{tabular}




\begin{tabular}{|c|c|c|}
\hline \multirow[t]{2}{*}{ Vontade de Saber } & $\begin{array}{l}\text { "História é o campo do conhecimento dedicado } \\
\text { ao estudo das ações dos seres humanos no } \\
\text { tempo e no espaço. Esse estudo envolve as } \\
\text { realizações humanas, as transformações } \\
\text { sociais, politicas e culturais que ocorrem nas } \\
\text { sociedades, bem como as permanências, isto é, } \\
\text { aquilo que pouco mudou ao longo do tempo. } \\
\text { A História contribui para a compreensão das } \\
\text { sociedades e suas caracteristicas ao longo do } \\
\text { tempo: organizações, transformações, instituições, } \\
\text { mudanças, rupturas, simultaneidades, } \\
\text { permanências, além de semelhanças e diferenças } \\
\text { que existem entre elas e, também, das relaçốes } \\
\text { entre os seres humanos que as constituem" p.16. }\end{array}$ & $\begin{array}{l}\text { "Os seres humanos passaram por grandes transformações } \\
\text { físicas e culturais durante os períodos paleolítico e neolitico"; } \\
\text { "Costuma-se utilizar as técnicas de fabricação de ferramentas } \\
\text { como elemento de separação entre os periodos históricos } \\
\text { chamados Paleolítico e Neolítico." p. } 41 \text {. }\end{array}$ \\
\hline & $\begin{array}{l}\text { "[...]ciência que nos ajuda a entender as } \\
\text { transformações e as permanências em } \\
\text { diferentes periodos e sociedades." } \\
\text { "[...] contar histórias; viver a história, estudar } \\
\text { História...Então, a palavra "história" não quer } \\
\text { dizer sempre a mesma coisa!" } \\
\text { "[...] Pesquisar o passado é uma forma de saber } \\
\text { quem somos, de onde viemos, por que pensamos e } \\
\text { vivemos de uma maneira e não de outra. O passado } \\
\text { também ajuda a entender por que nossa cidade tem }\end{array}$ & $\begin{array}{l}\text { "Havia história antes da história? } \\
\text { A expressão "Pré-história" quer dizer anterior à História } \\
\text { (pré=antes). Ela indica o enorme período compreendido entre } \\
\text { o aparecimento dos seres humanos sobre a terra (há mais de } \\
5 \text { milhões de anos) e o surgimento da escrita, que, em alguns } \\
\text { lugares, ocorreu no final do quarto milênio antes de cristo. Isso } \\
\text { significa que todo o periodo anterior ao surgimento da escrita } \\
\text { não seria considerado parte da História. }\end{array}$ \\
\hline Projeto Mosaico & $\begin{array}{l}\text { determinada característica ou por que nosso pais se } \\
\text { desenvolve de um jeito e não de outro. p.11,14 e } 15 .\end{array}$ & $\begin{array}{l}\text { Há cerca de } 200 \text { anos os historiadores se baseavam nos } \\
\text { textos escritos pelos povos antigos para entender seu } \\
\text { passado. Assim, acreditavam que os povos do passado que } \\
\text { não possuiam escrita não poderiam ser estudados - e, } \\
\text { portanto, não teriam história. Daí criaram a expressão "Pré- } \\
\text { história" para denominar o período em que viveram esses } \\
\text { povos que não dominavam a escrita. } \\
\text { Com o tempo, os historiadores descobriram que desenhos, } \\
\text { moradias e ferramentas deixados pelos povos pré-históricos } \\
\text { também revelavam muito sobre seu passado. Ou seja, } \\
\text { entenderam que era possivel contar sua história utilizando } \\
\text { documentos não escritos. Apesar disso, a expressão "Pré- } \\
\text { história" continuou sendo usada para definir o periodo anterior } \\
\text { à invencão da escrita." p.25 }\end{array}$ \\
\hline Historiar & $\begin{array}{l}\text { "[...] a História, como ciência interpreta as } \\
\text { experiências humanas ao longo do tempo. } \\
\text { Conhecendo essas interpretações, podemos } \\
\text { adquirir consciência do que fomos (passado) } \\
\text { para transformar o que somos (presente). } \\
\text { Por exemplo, no caso do nosso país, percebemos a } \\
\text { existência de grandes desigualdades sociais entre } \\
\text { ricos e pobres. Assim, os estudos de história } \\
\text { brasileira podem nos ajudar a compreender os } \\
\text { motivos dessas desigualdades. Sem consciência } \\
\text { histórica, podermos achar tudo isso muito "natural" e } \\
\text { não enxergar uma maneira de modificar essa } \\
\text { situação. Quando adquirimos conhecimento } \\
\text { histórico, percebemos que, se algumas coisas } \\
\text { mudaram no passado, também podem ser mudadas } \\
\text { no presente. } \\
\text { Nesse sentido, os estudos de História podem } \\
\text { despertar a consciência de cada um de nós para a } \\
\text { tarefa de construir uma sociedade mais justa, com } \\
\text { menos desigualdade entre as pessoas, } \\
\text { independementelde idade, sexo, origem social, cor } \\
\text { da pele e religiâo. Sem consciência histórica." p.25 }\end{array}$ & $\begin{array}{l}\text { "Atualmente, os estudiosos não dão uma importância tão } \\
\text { grande para essa distinção entre fontes escritas e não } \\
\text { escritas. Para eles, há várias formas de registro do } \\
\text { passado humano que podem ser interpretadas } \\
\text { historicamente. Além disso, o ser humano, desde que } \\
\text { surgiu na Terra é sempre um ser histórico. Apesar de } \\
\text { criticas mais recentes, o termo "Pré-história" continua } \\
\text { sendo usado para referir-se ao periodo inicial da } \\
\text { existência humana sobre a Terra. Neste livro também, } \\
\text { eventualmente, podemos nos referir a esse termo - } \\
\text { sabendo que esse período faz parte da História como } \\
\text { todos os outros." p.40 e } 41\end{array}$ \\
\hline
\end{tabular}

Fonte: ARAGÃO, 2019, p. 80 
ideia de História como se percebe ao analisar o quadro 2. As abordagens nas coleções didáticas não dialogam com uma História meramente factual. Nota-se que os livros defendem que o conhecimento histórico é mutável e que ao longo da escolarização promoverá debates e construções que darão subsídios para problematizações acerca da investigação histórica. As produções didáticas em maior ou menor grau assimilam os debates acadêmicos e as perspectivas e redefinições que ocorrem nos conceitos de História, adequando-os aos novos redirecionamentos do público escolar.

Nos livros História, Sociedade e Cidadania (FTD), Vontade de Saber (FTD) e Projeto Mosaico (Scipione) são dadas maiores importâncias as noções de mudança, permanência e transformação ao longo do tempo em diferentes períodos sociais para o entendimento da nossa sociedade atual. Esse entendimento envolve as realizações humanas e as transformações sociais políticas e culturais em diferentes ritmos (temporais) e contextos próprios.

Nos livros Projeto Araribá (Moderna) e Historiar (Saraiva) a noção de História é direcionada para versões e narrativas consistentes construídas para o entendimento dos processos históricos através dos documentos, acontecimentos e informações que se cruzam, se avaliam e são verificadas. Os livros também trazem mais de um paradigma historiográfico para mostrar possíveis e distintos caminhos da interpretação histórica, indicando uma pluralidade de visões teóricas, é o que podemos perceber do texto abaixo extraído do livro Projeto Araribá:

Dois trabalhos teóricos nas ciências humanas foram responsáveis pela introdução de novos temas e personagens nas pesquisas de história, mudando radicalmente a forma como o passado era visto e estudado.

O primeiro trabalho foi feito pelos alemães Karl Marx (1818-1883) e Friedrich Engels (1820-1895). Eles elaboraram a ideia de que as mudanças na história tinham sido movidas sempre pela luta entre a classe dominante e a classe oprimida.

[...] No trabalho que desenvolveram, passaram a valorizar a ação das pessoas comuns, suas condições de trabalho, suas lutas, seu cotidiano, seus costumes. É a chamada história vista de baixo.

O segundo trabalho transformou os estudos de história começou a ser publicado por historiadores franceses em 1929 e ficou conhecido como Escola dos Annales. O grupo francês ampliou a noção que se tinha de documento histórico. Além das fontes escritas, pinturas, esculturas, ferramentas, moradias, fósseis e vários outros registros passaram a ser examinados como fonte para compreender 0 passado" (APOLINÁRIO, 2014, P.20-21). 
Ao fazer o mesmo exercício teórico com o termo Pré-história percebe-se que os livros trazem as divisões tradicionais da Pré-história como Paleolítico, Neolítico e Idade dos metais. Alguns livros salientam que esses períodos são estudados por arqueólogos, principalmente, para entender a dinâmica dos agrupamentos humanos e da cultura material do passado longínquo. Porém, algumas passagens textuais merecem uma observação mais perspicaz. O livro Projeto Araribá (Moderna) afirma que "Ao estudar o passado primitivo da história humana, os pesquisadores deram o nome de Paleolítico", esse trecho encontra-se no quadro 02, ocorre nessa passagem a substituição do termo Pré-história por uma associação ao um "passado primitivo". A ideia de um homem primitivo, um homem antigo, atrasado perpassa sutilmente através da literatura didática e reproduz veladamente estereótipos e preconceitos.

Os 5 (cinco) livros pesquisados "excluem" o termo Pré-história. A fundamentação mais utilizada pelos autores é considerarem inadequado. O livro Projeto Mosaico (Scipione) problematiza o termo: "Havia história antes da história? A expressão "Pré-história" quer dizer anterior à História (pré=antes)." "Ela indica o enorme período compreendido entre o aparecimento dos seres humanos sobre a terra (há mais de 5 milhões de anos) e o surgimento da escrita", texto elencado no quadro 02 . O livro também propõe uma reflexão e um questionamento historiográfico, ao dividir a História em período de escrita, não-escrita, os historiadores se baseavam em documentos apenas escritos, uma concepção do século XIX. Hoje, sabemos que o domínio gráfico não é um critério determinante para a construção e registro da História de nenhum povo.

Ao mesmo tempo em que o termo é "contestado", os livros trazem explicações e divisões atreladas a esse período histórico que reforçam sua utilização na escola. No livro Historiar (Saraiva) tem-se o mesmo raciocínio do Projeto Mosaico (Scipione), afirmando que os historiadores não se importam e nem fazem a distinção entre fontes escritas e não-escritas e que existem diferentes registros e formas de interpretar o passado humano, mas o termo Pré-história pode ser usado "eventualmente" para se referir ao período inicial da existência humana.

Pode-se dizer que os livros trazem as divisões mais tradicionais da História e da Pré-história, respectivamente, Pré-história, História Antiga, História Medieval, 
História Moderna e História Contemporânea e Paleolítico, Neolítico e Idade dos metais. Os livros mostram as inadequações inerentes ao termo Pré-história, como foi visto, entretanto, justificam o uso do termo pela força da tradição historiográfica/escolar. Existem críticas ao conceito e até livros que não mencionam o termo, como o Vontade de Saber (FTD), contudo, acabam fazendo uso indiretamente através da periodização tradicional.

Nos temas debatidos e mantidos na cultura escolar se faz necessário perceber a atualização historiográfica, seja na linguagem, no conteúdo ou na crítica aos termos estudados (História e Pré-história). Na linguagem podemos entender que uma atualização está ligada aos novos termos, ao discurso que se aproxima dos debates atuais. Esses discursos circulam nos conteúdos que são reformulados. A categoria atualização historiográfica, posta no quadro 3 a seguir, está ligada a novos olhares sob os conteúdos abordados que tratem o conceito de História sob o ponto de vista ético pautado no respeito às diferenças culturais e na vivência social partilhada em princípios humanizadores. Ao passo que entender a pluralidade dos espaços, dos tempos e dos processos históricos fazem parte de uma perspectiva que inova na forma de assimilar o conhecimento histórico. A partir da montagem do quadro 3 , a seguir, poderemos fazer uma análise comparativa das narrativas nas coleções dos aspectos inovadores. 


\begin{tabular}{|c|c|c|c|}
\hline Coleção (Iivro) & Categoria & História & Pré-história \\
\hline $\begin{array}{l}\text { História, } \\
\text { Sociedade e } \\
\text { Cidadanias }\end{array}$ & & $\begin{array}{l}\text { "Queim faz a História? } \\
\text { A História nảo é feita apenas pelos grandes } \\
\text { personagens (reis, generais, presidentes), mas } \\
\text { por todos nós, isto é, por pessoas como eu, } \\
\text { vocé, sua professora, a diretora, o prefeito etc.; } \\
\text { por grupos como o dos artesăo, dos idosos, } \\
\text { dlos soldados, dos ricos, das mulheres, das } \\
\text { crianças etc."p. } 20\end{array}$ & $\begin{array}{l}\text { "[-..] As culturas são differentes entre si; apenas isso. } \\
\text { Cada cultura tem o seu valor e nazo ha uma cultura } \\
\text { superior a outra. Conforme a Antropologia, nenhum } \\
\text { povo pode ser chamado de "selvagem" ou "primitivo" } \\
\text { porque se veste, se enfeita, se alimenta ou pensa } \\
\text { diferente do outro." p. } 29\end{array}$ \\
\hline Projeto Araribã & & $\begin{array}{l}\text { "eles (historiadores) admitem a existéncia de } \\
\text { várias: interpretaçōes ou relatos sobre o } \\
\text { mesmo acontecimento. O fato de ser possivel } \\
\text { mais de uma vers.jo sobre um mesmo } \\
\text { acontecimento possibilita construir uma visão } \\
\text { mais próxima do que de fato ocorreu" p.20 }\end{array}$ & $\begin{array}{l}\text { "Muitos estudiosos criticarn esse divis do por levar } \\
\text { em consideração apenas acontecimentos da história } \\
\text { europeia e anular a história de outros povos" p. } 28 \text {. }\end{array}$ \\
\hline $\begin{array}{c}\text { Vontade de } \\
\text { Saber }\end{array}$ & $\begin{array}{c}\text { Inovação } \\
\text { Historiogrăfica } \\
\text { (atualizaçäo) }\end{array}$ & 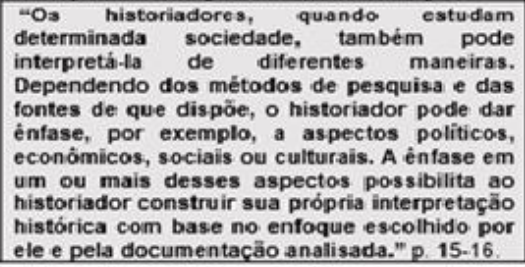 & $\begin{array}{l}\text { "Arqueologia } \\
\text { A Arqueologia é uma área do conhecimento que estuda } \\
\text { o moodo de vida dos povos do passado por meio da } \\
\text { análise dos vestigios materiais por eles produzidos. } \\
\text { Muito do que sabemos sobre a Antiguidade, por } \\
\text { exemplo, se deve ao trabalho dos arqué́logos." p. } 26\end{array}$ \\
\hline $\begin{array}{l}\text { Projeto } \\
\text { Mosaico }\end{array}$ & & $\begin{array}{l}\text { "Eles (historiadores) anslis.am os vários } \\
\text { acontecimentos ocorridios no passado e thes } \\
\text { däio um sentido, ou seja, transformam a história } \\
\text { vivida pelos seres humanos em uma história } \\
\text { contada. Para isso eles interpretam o passado. } \\
\text { utilizando documentos (ou fontes históricas)." p.15 }\end{array}$ & 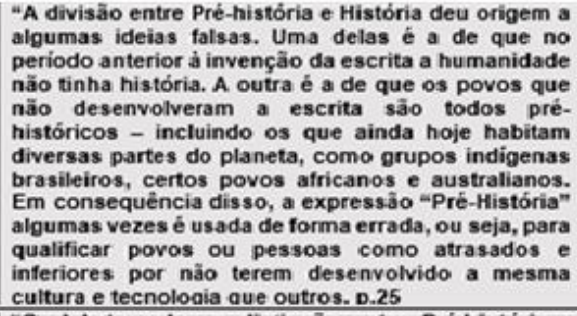 \\
\hline Historiar & & $\begin{array}{l}\text { "I...] A palavra história tem diversos sentidos. } \\
\text { [...] História - conhecimento. } \\
\text { A palavra história vem do grego e pode ser } \\
\text { relacionada aos sentidos de "procurar saber" } \\
\text { ou "informar-se". Nesse caso a história se } \\
\text { referia a uma pesquisa sobre algo que ocorreu } \\
\text { no passado. Era uma narração, um relato, uma } \\
\text { interpretacăo das informaçoes procuradas. } \\
\text { Posteriormente, essa palavra passou a ser } \\
\text { usada para denominar os conhecimentos } \\
\text { sobre a vida das pessoas e dos povos ao longo } \\
\text { do tempo. Assim, a história tornou-se área do } \\
\text { conhecimento na qual se estuda como os seres } \\
\text { humanos viveram, desde o passado mais } \\
\text { distante até os nossos dias. } \\
\text { "[...]Um historiador pode utilizar diversos tipos } \\
\text { de fonte de pesquisa, como, por exemplo, } \\
\text { documentos politicos, dados económicos, } \\
\text { obras de ficção, entrevistas de pessoas e } \\
\text { objetos do cotidiano" } \\
\text { p.22, } 24 \text { e } 25\end{array}$ & $\begin{array}{l}\text { "O debate sobre a distinção entre Pré-história e } \\
\text { História. } \\
\text { Uma das periodizações mais conhecidas e debatidas } \\
\text { estabelece a distinçăo entre um periodo anterior à } \\
\text { invenção da escrita e outro posterior à escrita. Nessa } \\
\text { divisăo, convencionou-se chamar de "pré-história" o } \\
\text { longo periodo que se inicia com o surgimento do ser } \\
\text { humano com o periodo em que surgiu a escrita, por } \\
\text { volta de } 4000 \text { a.C. O período posterior foi chamado } \\
\text { de "histórico". } \\
\text { A distinçäo entre História e Pré-história foi criada por } \\
\text { historiadores europeus que viveram no século XIX. } \\
\text { Eles davam grande importáncia às fontes escritas } \\
\text { porque supunham que elas eram mais confiáveis. } \\
\text { Atualmente, os estudiosos não dảo uma importância } \\
\text { tão grande para essa distinção entre fontes escritas } \\
\text { e não escritas. Para eles, há várias formas de registro } \\
\text { do passado humano que podem ser interpretadas } \\
\text { historicamente. p.40 e } 41\end{array}$ \\
\hline
\end{tabular}

\section{Quadro 3 - Inovação Historiográfica (atualizada)}

As 5 (cinco) coleções estudadas apresentam perspectivas atualizadas sobre o conceito de História. A inovação se faz presente na forma como os elementos históricos são trabalhados: a função dos sujeitos históricos na narrativa, a construção histórica a partir de um diálogo com o tempo presente e a relação teórica estabelecida.

Nos livros História, Sociedade e Cidadania (FTD), Projeto Araribá (Moderna), Vontade de Saber (FTD) e Projeto Mosaico (Scipione) trazem os sujeitos históricos formados por grupos sociais e funções diversas como: artesãos, idosos, reis,

Fonte: ARAGÃO, 2019, p. 87 
soldados, crianças, pobres, ricos, generais, presidentes etc. Ambientados em espaços plurais da sociedade como: nas Igrejas, Terreiros, Câmara dos Deputados, Exércitos, Sindicatos, Usinas etc. O contato da História com esses atores sociais e em diferentes cenários representa uma atualização historiográfica à medida que a narrativa histórica deixa de observar apenas o papel daqueles sujeitos que detinham o poder na sociedade para valorizar outras instancias sociais, não privilegiadas pela História oficial em outros momentos da historiografia.

Em contraste com uma perspectiva histórica única, linear e de verdade absoluta, os livros também abordam os acontecimentos históricos por diferentes ângulos, gerando diferentes interpretações e a possibilidade de mais de uma versão para as narrativas construídas. Assim, o livro Historiar (Saraiva) aborda a construção do sentido da História em tempos diversos, foi o único livro, das 5 (cinco) coleções analisadas, que ampliou a contextualização do conceito de História, mostrando ao aluno os regimes de historicidades na construção do conceito de História.

Os livros História, Sociedade e Cidadania (FTD), Projeto Araribá (Moderna) em relação à Pré-história trazem pequenas atualizações. O primeiro, faz referência à cultura como fator de diferenciação entre os povos. Isso constitui uma crítica às narrativas históricas que conservaram a ideia de superioridade e inferioridade entre povos, a partir de traços culturais ou estágios civilizatórios. A inovação é no sentido valorizar a cultura como identidade de diferentes povos, promovendo o respeito em detrimento da utilização de termos como "selvagem" ou "primitivo" que condena culturas, como as dos povos originários do Brasil, ao atraso, algo errôneo que não pode ser perpetuado em livro didático na atualidade.

A obra Vontade de Saber (FTD) se diferencia das demais por não apresentar o termo Pré-história em seu texto didático. Os livros Projeto Mosaico (Scipione) e Historiar (Saraiva), utilizam as divisões tradicionais, mas trazem uma reflexão sobre os dois termos História e Pré-história: chama de uma falsa construção a divisão de História e Pré-história em função da escrita, pois o período da humanidade anterior à invenção da escrita é História e representa o período mais longo e antigo dos registros humanos.

Sem dúvida, o debate mais inovador promovido nos livros didáticos analisados em relação ao termo Pré-história tem a ver com a questão da escrita. 
Se tudo é história, não podemos classificar povos e culturas como pré-históricos por não possuir um sistema de escrita. Os livros didáticos de História inovam em suas narrativas ao debater essa questão. E o não debate pode suscitar em discriminação e em uma visão equivocada sobre os povos mais antigos.

\section{Considerações Finais}

Nos livros didáticos estudados predomina a visão da História baseada nas inflexões provocadas pela geração da Escola dos Annales no modo de escrever a história. Estes paradigmas estão presentes nos livros e podem ser percebidos nas problematizações, nas narrativas e na importância dada a cultura. O conceito de História debatido nos livros indica que a História é o acontecimento (fato) e a sua reconstituição pelos historiadores. Significa que o historiador através de métodos científicos e análises metodológicas consistentes, apoiadas em fontes históricas, constrói a narrativa histórica. Essas narrativas carregam as verdades relativas à sua época.

Por isso, a História se apresenta dinâmica como um processo em construção que se refaz por novas pesquisas históricas. Já não comporta mais um conhecimento inalterado, de datas exatas e sem questionamentos reflexivos. A História carrega o sentido posto pela historiografia de sua época e esses sentidos são ressignificados com o tempo, inclusive, nos livros didáticos.

As definições encontradas nos livros didáticos em relação ao conceito de Pré-história ainda fazem referência a ideia temporal da História depois da escrita, ou seja, a uma divisão mais clássica que necessita ser problematizada, pois diferenciam e hierarquizam os grupos sociais. O conceito de Pré-história vem passando por ressignificações e por muitas críticas, inclusive, pelas coleções didáticas estudadas. Existe um movimento tímido na literatura didática para o desuso do conceito em função de novos termos que represente uma História menos colonial como é o caso da nomenclatura, História Indígena, termo utilizado para se referir aos nossos primeiros habitantes e não mais como povos préhistóricos.

Modificar paradigmas históricos, ressignificar conceitos, lançar uma nova forma de escrever a História é algo que acontece gradativamente ao toque do 
tempo e das percepções de mudanças que ocorrem na sociedade por meio de muita pesquisa e de questionamentos. O debate nos textos escolares, para melhor compreensão da construção das narrativas historiográficas pelos alunos, sobre as teorias da História em linguagem didática não impediu de se ter uma argumentação qualitativa e de produzir uma narrativa atualizada sob muitos aspectos das tendências historiográficas.

\section{Referências}

ALBUQUERQUE JUNIOR, Durval Muniz. Fazer defeitos nas memórias: para que servem a escrita e o ensino da história?. In: GONÇALVES, Márcia de Almeida; ROCHA, Helenice; REZNIK, Luís; MONTEIRO, Ana Maria (org.). Qual o valor da história hoje?. Rio de Janeiro: FGV, 2012.

APOLINÁRIO, Maria Raquel. Projeto Araribá: história. 4. ed. São Paulo: Moderna, 2014.

ARAGÃO, Luiz Adriano Lucena. História e pré-história: investigando os usos desses conceitos nos livros didáticos de história. 2019. 154 f. Dissertação (Mestrado em História) - Universidade Federal Rural de Pernambuco, Recife, 2019. Disponível em: http://www.tede2.ufrpe.br:8080/tede2/handle/tede2/8391. Acesso em: 16 jun. 2020.

BARDIN, Laurence. Análise de conteúdo: 1977. Lisboa: Edições, 2010. v. 70.

BARROS, José D'Assunção. Teoria da história: os primeiros paradigmas: positivismo e historicismo. Rio de Janeiro: Vozes, 2011.

BLOCH, Marc. Apologia da História ou o ofício do historiador. Rio de Janeiro: Jorge Zahar, 2002. BOULOS JUNIOR, Alfredo. História, sociedade \& cidadania. 3. ed. São Paulo: FTD, 2015.

BRASIL. Fundo Nacional de Desenvolvimento da Educação. Programas do Livro. Brasília: $2017 . \quad$ DEC, em: http://www.fnde.gov.br/programas/programas-do-livro/livro-didatico/dadosestatisticos. Acesso em: 12 maio 2017.

BRASIL. Fundo Nacional de Desenvolvimento da Educação. Programas do Livro. Brasília: MEC, 2017. Disponível em: http://www.fnde.gov.br/component/k2/item/518-histórico. Acesso em: 12 maio 2017.

CAIMI, Flavia Eloisa. As disciplinas escolares no contexto do PNLD: avanços, lacunas e desafios na avaliação do livro didático. Revista de Educação Pública, Rio de Janeiro, v. 24, n. 57, p. 525-543, 2015. 
CAIMI, Flavia Eloisa. O que sabemos (e o que não sabemos) sobre o livro didático de história: estado do conhecimento, tendências e perspectivas. In: GALZERANI, Maria Carolina Bovério; BUENO, João Batista Gonçalves; PINTO JUNIOR, Arnaldo. Paisagens da pesquisa contemporânea sobre livro didático de história. Campinas: UNICAMP, 2013. p. 35-52.

CHOPPIN, Alain. História dos livros e das edições didáticas: sobre o estado da arte. Educação e Pesquisa, São Paulo, v. 30, n. 3, p. 549-566, 2004.

CORRÊA, Ângelo Alves. Longue Durée: história indígena e arqueologia. Cienc. Cult., São Paulo, v. 65, n. 2, p. 26-29, jun. 2013.

COTRIM, Gilberto. Historiar. 2. ed. São Paulo: Saraiva, 2015.

FREITAS, Itamar. Livro didático de história: definições, representações e prescrições de uso. In: OLIVEIRA, Margarida Dias de; OLIVEIRA, Almir Félix Bueno de. Livros didáticos de História: escolhas e utilizações. Natal: Editora da UFRN, 2009. p. 11-19.

GATTI JÚNIOR, Décio. A escrita escolar da história: livro didático e ensino no Brasil (1970-1990). Porto Alegre: Edusc, 2004.

GLEZER, Raquel. Novos livros \& velhas ideias. Revista Brasileira de História, São Paulo, v. 4, n. 7, 1984.

GOSDEN, Chris. Pré-história. Porto Alegre: L\&PM POCKET, 2012.

GUIMARÃES, Selva. Didática e prática de ensino de História: experiências, reflexões e aprendizados. 13. ed. São Paulo: Papirus, 2012. (Coleção Magistério: formação e trabalho pedagógico).

KOSELLECK, Reinhart. Futuro Passado: contribuição à semântica dos tempos históricos. Rio de Janeiro: Contraponto, 2006.

KOSELLECK, Reinhart. Uma história dos conceitos: problemas teóricos e práticos. Revista Estudos Históricos, Rio de Janeiro, v. 5, n. 10, p. 134-146, 1992.

KOSELLECK, Reinhart; MEIER, Christian; GUNTHER, Horsy; ENGELS, Odilo. $O$ conceito de História. Belo Horizonte: Autêntica, 2013.

MINAYO, Maria Cecilia de Souza. Ciência, técnica e arte: o desafio da pesquisa social. In: MINAYO, Maria Cecilia Souza (org.). Pesquisa social: teoria, método e criatividade. Petrópolis: Editora Vozes, 2010. p. 9-29.

PELLEGRINE, Marco César. Vontade de saber história. São Paulo: FTD, 2015.

REIS, José Carlos. Teoria \& história: tempo histórico, história do pensamento histórico ocidental e pensamento brasileiro. Rio de Janeiro: FGV, 2012. 
TRIGGER, Bruce Graham. Além da história: os métodos da pré-história. Tradução de Ulpiano Bezerra de Menezes. São Paulo: Universidade de São Paulo, 1973. p. 1-159.

TRIGGER, Bruce. História do pensamento arqueológico. São Paulo: Odysseus, 2004.

VEYNE, Paul Marie. Como se escreve a história: Foucault revoluciona a história. 3. ed. Brasília: Ed. Unb, 1995.

VICENTINO, Cláudio. Projeto mosaico: história. 3. ed. São Paulo: Scipione, 2016. 